\title{
Erratum to: Dose-dependent sigma-1 receptor occupancy by donepezil in rat brain can be assessed with ${ }^{11} \mathrm{C}-\mathrm{SA} 4503$ and microPET
}

\author{
Nisha K. Ramakrishnan • Anniek K. D. Visser • Marianne Schepers • Gert Luurtsema • \\ Csaba J. Nyakas • Philip H. Elsinga • Kiichi Ishiwata • Rudi A. J. O. Dierckx • \\ Aren van Waarde
}

Published online: 8 April 2014

(C) Springer-Verlag Berlin Heidelberg 2014

\section{Erratum to: Psychopharmacology}

DOI 10.1007/s00213-014-3533-2

The original version of this article inadvertently contained a mistake. Figure 4 was corrupted in the original publication of this paper. Here is a corrected and updated version of this figure.

Fig. 4 a Lassen plot as extended by Cunningham. Difference between the $V_{\mathrm{T}}$ of control and treated groups was plotted versus $V_{\mathrm{T}}$ of control group. The dots represent individual brain regions, b receptor occupancy plotted against $\log$ donepezil dose to obtain $\mathrm{ED}_{50}$
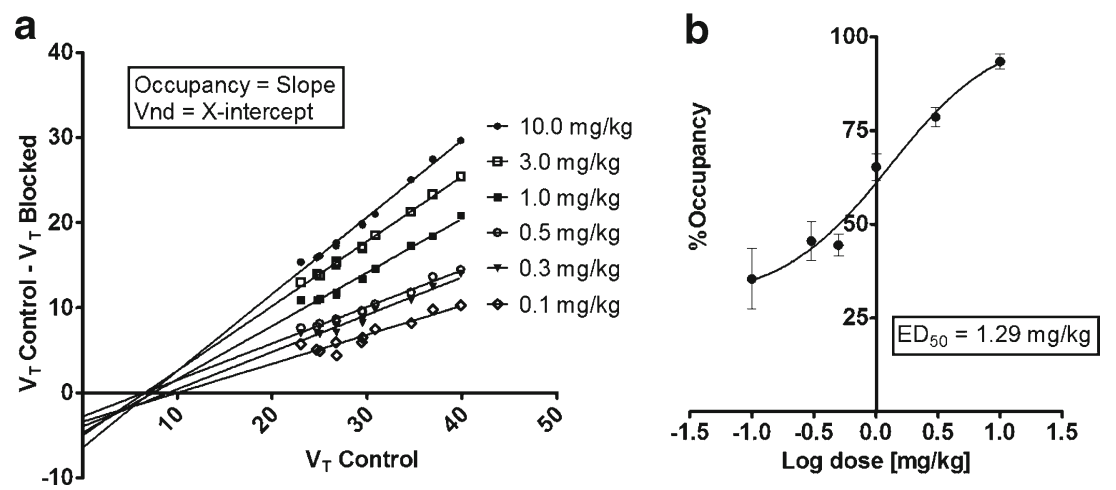

The online version of the original article can be found at http://dx.doi.org/ 10.1007/s00213-014-3533-2.

N. K. Ramakrishnan · A. K. D. Visser · M. Schepers $\cdot$

G. Luurtsema $\cdot$ P. H. Elsinga $\cdot$ R. A. J. O. Dierckx $\cdot$

A. van Waarde $(\bowtie)$

Department of Nuclear Medicine and Molecular Imaging, University of Groningen, University Medical Center Groningen, Hanzeplein 1, 9713 GZ Groningen, The Netherlands

e-mail: a.van.waarde@umcg.nl

C. J. Nyakas

Brain Physiology Research Unit, Semmelweis University, Budapest,

Hungary

K. Ishiwata

Tokyo Metropolitan Institute of Gerontology, Tokyo, Japan 